\title{
A EDUCAÇÃO PELO TRABALHO NA SAÚDE: CONEXÕES ENTRE FORMAÇÃO E PRÁTICAS NOS SERVIÇOS DE SAÚDE
}

\author{
EDUCACIÓN A TRAVÉS DEL TRABAJO EN SALUD: CONEXIONES ENTRE \\ FORMACIÓN Y PRÁCTICAS EN LOS SERVICIOS DE SALUD
}

\section{EDUCATION THROUGH WORK IN HEALTH: CONNECTIONS BETWEEN FORMATION AND PRACTICES IN HEALTH SERVICES}

\author{
Victória Ângela Adami BRAVO ${ }^{1}$ \\ Tiago Rocha PINTO² \\ Eliana Goldfarb CYRINO ${ }^{3}$
}

RESUMO: O artigo busca refletir sobre a educação pelo trabalho em saúde como um processo político-educacional amplo e crítico diante da concretude do Sistema Único de Saúde (SUS), além de discutir a centralidade do Programa de Educação pelo Trabalho para a Saúde (PET-Saúde) no interior do movimento pela reformulação das graduações da saúde no Brasil. Trata-se de estudo de natureza teórico-conceitual realizado a partir de análise documental sobre a história e bases dos programas ministeriais voltados à educação pelo trabalho na saúde e suas contribuições trazidas ao longo das últimas duas décadas. É possível reconhecer que o PET-Saúde tem fomentado a valorização da formação pelo trabalho a partir da sua composição junto aos serviços de saúde, estimulando parcerias e arranjos com secretarias e serviços que vão muito além dos muros da universidade, potencializando uma formação concatenada aos preceitos do SUS e com as necessidades de saúde da população brasileira.

PALAVRAS-CHAVE: Formação profissional. Educação pelo trabalho na saúde. Atenção primária à saúde. Educação médica.

RESUMEN: El artículo busca reflexionar la educación por el trabajo en salud como un proceso político-educativo amplio y crítico ante la concreción del Sistema Único de Salud (SUS), además de discutir la centralidad del programa Educación por el trabajo para la salud (PET-Saúde) dentro del movimiento de reformulación de las titulaciones en salud en Brasil. Se trata de un estudio teórico-conceptual realizado a partir del análisis documental de la historia y fundamento de los programas ministeriales orientados a la educación a través del trabajo en salud y sus aportes aportados durante las dos últimas décadas.. Es posible reconocer que PET-Saúde ha impulsado la valorización de la formación a través del trabajo basado en su composición con los servicios de salud, estimulando alianzas y arreglos con departamentos y servicios de salud que trascienden

\footnotetext{
${ }^{1}$ Mestre em Saúde Coletiva pela Faculdade de Medicina - Universidade Estadual Paulista (UNESP). ORCID: https://orcid.org/0000-0003-3430-2560.E-mail: victoria_bravo86@hotmail.com

${ }^{2}$ Universidade Federal de Uberlândia (UFU), Umuarama, Uberlândia - MG - Brasil. Professor Adjunto do Departamento de Saúde Coletiva. ORCID: https://orcid.org/0000-0003-4834-2897. E-mail: tiago.rocha@ufu.br ${ }^{3}$ Universidade Estadual Paulista (UNESP), Botucatu - SP - Brasil. Professora Assistente do Departamento de Saúde Pública. ORCID: https://orcid.org/0000-0002-6526-3528. E-mail: ecyrino@fmb.br
} 
los muros de la universidad. potenciando una formación concatenada con los preceptos del SUS y con las necesidades de salud de la población brasileña.

PALABRAS CLAVE: Formación professional. Educación a través del trabajo en salud. Atención primaria de salud. Educación médica.

ABSTRACT: The article seeks to think the education through work in health as a broad and critical political-educational process in view of the concreteness of the Unified Health System (SUS), in addition to discussing the centrality of the Education through work for health program (PET-Saude) within the movement for the reformulation of health degrees in Brazil. This is a theoretical-conceptual study carried out based on documentary analysis of the history and basis of ministerial programs aimed at education through health work and the contributions brought by them over the past two decades. It is possible to recognize that PETSaude has promoted the valorization of formation through work based on its composition with health services, stimulating partnerships and arrangements with health departments and services that go far beyond the walls of the university, potentializing a formation concatenated with SUS precepts and with the health needs of the Brazilian population.

KEYWORDS: Professional formation. Education through work in health. Primary health care. Medical education.

\section{Introdução}

\section{Pressupostos dos movimentos pela reformulação dos cursos de graduação da saúde}

Desde a instituição do Sistema Único de Saúde (SUS) na Constituição Federal do Brasil, em 1988, um de seus grandes desafios têm sido a tarefa de reorganização da atenção à saúde, valorizando-se a integralidade do cuidado e a ruptura com a lógica curativa e a atenção fragmentada, ainda hegemônicas no sistema de saúde.

A oitava Conferência Nacional de Saúde (CNS) realizada em 1986 é considerada um marco para a saúde coletiva do país, com influência direta na instituição do SUS. Em seu relatório foram apresentadas inúmeras contribuições para a mudança do sistema de saúde brasileiro como um todo, inclusive no que se refere à necessidade de aproximação entre o processo formativo e o cotidiano dos serviços de saúde, catalisando mudanças nas práticas e na formação profissional em saúde ainda arraigadas no paradigma biomédico.

Entre outras questões, compreendeu-se que para construir um sistema público de saúde com qualidade, também era necessário realizar mudanças na formação dos profissionais de saúde. Nesta perspectiva, se apresentaram nas últimas décadas uma série de políticas e programas indutores de mudanças no perfil do profissional e do trabalho na saúde, que, fomentados pelo Ministério da Saúde (MS) em parceria com o Ministério da Educação 
(MEC), vieram a afirmar sua tarefa de ordenar e regulamentar a formação dos profissionais de saúde em todo território nacional. (BRASIL, 2004; 2007)

A partir da criação da Secretaria de Gestão do Trabalho e da Educação na Saúde (SEGETS) no MS, em 2003, foi possível implementar a Política Nacional de Educação Permanente em Saúde (PNEPS) (BRASIL, 2004), chamando para si a responsabilidade institucional por uma formação condutora de transformações das práticas profissionais e das estratégias de organização da atenção à saúde, incluindo a compreensão de necessárias mudanças nas formações das graduações em saúde.

Cardoso et al.. (2017) trazem rica discussão sobre as bases conceituais da Educação Permanente em Saúde (EPS) na perspectiva da educação pelo trabalho, a qual consideram enquanto uma matriz qualificadora para a assistência à saúde da população. O referido estudo discute que com a expansão do sistema de saúde brasileiro, ocorrida a partir dos anos 1970, desencadeou-se a necessidade da formação de trabalhadores a partir de modelos políticopedagógicos comprometidos com uma formação contextualizada e comprometida com a assistência à saúde da população, em oposição aos modelos de capacitação fora do ambiente de trabalho e voltados a uma transmissão unilateral e descontextualizada do conhecimento que não produz mudanças na prática como seria requerido.

Deste modo, a EPS se fundamenta numa pedagogia reflexiva de prática social e intervenção crítica na realidade. Assume como eixo estruturante a categoria trabalho, uma vez que é neste espaço que as atividades práticas individuais e coletivas são realizadas, o que pressupõe a participação ativa dos trabalhadores em seu próprio processo de aprendizagem. Assim, o trabalho revela-se como foco de atenção da gestão e da estruturação dos serviços sintonizados com as transformações do mundo (SAVIANI, 2006; CARDOSO et al., 2017).

A EPS propõe uma formação com a capacidade de provocar mudanças nos processos de trabalho, adotando valores condizentes com os princípios do SUS, como universalidade, equidade e integralidade, de forma a qualificar o acesso e acolhimento no cuidado, expressa isso no reconhecimento dos problemas de saúde, na sua amplitude e complexidade e na busca de soluções criativas para as demandas da equipe de saúde e que respondam às necessidades de usuários e da comunidade, a partir da criação de espaços de enfrentamento e reflexão sobre o cotidiano no trabalho (CARDOSO et al.., 2017).

Ramos (2009) discute a EPS reportando-se à integralidade da atenção como princípio que tem condições de fundamentar uma aproximação mais orgânica entre o mundo do trabalho, educação e da saúde na vida das pessoas. "Por esse princípio, a saúde nos remete a 
práticas e ações de sujeitos que cuidam das pessoas integralmente, onde os usuários dos serviços de saúde são seres humanos inteiros" (p. 52).

O desafio é possibilitar uma formação crítica, reflexiva e contextualizada, cuja práxis pedagógica supere o treinamento meramente técnico e tradicional, e passe a vislumbrar uma "formação de sujeitos éticos, críticos, reflexivos, colaborativos, históricos, transformadores, humanizados e com responsabilidade social" (CYRINO et al., 2015a p.5).

Contrapondo a visão tradicional do "conhecimento como produto, há hoje toda uma tendência de entendê-lo como processo que (...) exige do aprendiz capacidade de interpretação e ressignificação" (CUNHA, 1999, p.12). Para que este processo possa acontecer é preciso contar, também, com um profissional inquieto, que esteja disposto a fazer rupturas com a sua própria história profissional, normalmente marcada pela reprodução. Neste sentido, o profissional precisa "se expor no seu próprio processo de maturação, incluindo a dúvida epistemológica como ponto modal da sua concepção de conhecimento" (p.8).

Assumimos, como Ceccim e Feuerwerker (2004), que a política de educação em saúde deve ser capaz de impactar no ensino, na gestão, na atenção e no controle social, com implicações para formação de um profissional preparado e instrumentalizado para atuar na área da saúde. A formação pelo trabalho implica necessariamente na apropriação de conhecimentos que propiciem "ao sujeito conhecer e reconhecer a totalidade do processo do trabalho, ainda que ele venha a atuar em uma parte dessa totalidade" (RAMOS, 2009, p. 57).

Cabe ressaltar que são exemplos de protagonismo por reformas de ensino que dialogam com os movimentos de mudança na saúde e com o desenvolvimento do SUS, currículos e cursos de graduação integrados, bem como articulações ensino-serviço-trabalho e movimentos como a rede de Integração Docente Assistencial (IDA) e os projetos UNI, com envolvimento e participação de diversos países da América Latina, a Rede Unida, a CINAEM, o debate e a construção das Diretrizes Curriculares Nacionais, em 2001 e em 2014, o Programa Mais Médicos e a organização do Movimento Estudantil nas graduações da saúde (CYRINO et al., 2015b).

Neste processo, destaca-se o Programa Nacional de Reorientação Profissional em Saúde (Pró-Saúde) e o Programa de Educação pelo Trabalho para a Saúde (Pet-Saúde), como uma ação conjunta dos Ministério da Saúde (MS) e Ministério da Educação e Cultura (MEC), voltadas a provocar mudança na formação das profissões da saúde, com uma maior aposta em sua sustentabilidade ao longo dos anos (HADDAD et al., 2012). Tal cenário foi acompanhado pelo aumento de vagas de residências médicas em áreas prioritárias, as residências 
multiprofissionais do MS, bem como a Reestruturação e Expansão das Universidades Federais (Reuni), através da abertura de novos cursos de graduação na saúde.

Num contexto em que a temática da formação profissional em saúde vem se estabelecendo como uma agenda expressiva, tanto na realização de pesquisas como da construção de processos para intervenção nessa área (PEREIRA et al., 2016) é que o presente artigo busca refletir, por meio de pesquisa teórico-conceitual e documental, sobre a educação pelo trabalho na saúde como um processo político-educacional amplo e crítico diante da concretude do SUS. Pretende ainda discutir a centralidade do PET-Saúde no interior do movimento pela reformulação das graduações da saúde no Brasil, trazendo à tona algumas raízes da Educação pelo trabalho na saúde em conformidade com a problemática abordada. $\mathrm{O}$ presente trabalho encontrou na obra "Fundamentos da escola do trabalho" de Pistrak (1924/1981) a base teórica para a discussão da educação pelo trabalho, que é o cerne deste artigo.

Este artigo é parte de uma pesquisa de doutorado desenvolvida no Projeto Pró-Ensino na Saúde da Faculdade de Medicina de Botucatu, UNESP (2010-2018), com financiamento da CAPES (2237/2010). O estudo foi aprovado pelo Comitê de Ética em Pesquisa, da Faculdade de Medicina de Botucatu, FMB/UNESP, sob o parecer nº 2.648.649.

\section{A educação pelo trabalho na saúde: aproximações com Pistrak}

A obra "Fundamentos da escola do trabalho" (1924/1981), de Moisey Mikhaylovich Pistrak, é um importante marco conceitual em condições de sustentar um profícuo diálogo junto à temática educação pelo trabalho.

Educador socialista que viveu na Rússia pós-revolução de 1917. Pistrak influenciou as ideias pedagógicas em voga neste período. Questionou os conteúdos implícitos significativos da escola tradicional, indo além da discussão meramente metodológica para enfrentar os problemas de finalidade do ensino (TRAGTENBERG, 1981).

Considerado um dos mais influentes educadores russos pós-revolução, a obra de Pistrak é densa e extensa, embora poucas de suas obras tenham sido traduzidas para o português, como: A Escola-Comuna (2013) e Ensaios sobre a Escola Politécnica (2015), sendo o livro mais difundido no Brasil Fundamentos da escola do trabalho (1981) que, entre outros aspectos, trata da relação teoria e prática, da escola do trabalho, do trabalho na escola, do ensino e da auto-organização dos alunos (FREITAS, 1998). 
Tendo a teoria Marxista como base capaz de garantir a transformação da escola, Pistrak orientou uma proposta de prática do trabalho escolar. Com isso, "A Escola do Trabalho" pode ser compreendida como o resultado da prática pedagógica a partir de uma experiência concreta, fundamentada no estudo das relações do homem com a concretude da realidade presente e no processo de auto-organização dos alunos (TRAGTENBERG, 1981).

O objetivo de Pistrak na escola do trabalho, não foi o de formular uma nova teoria, mas de analisar seu surgimento em decorrência da prática escolar guiada pelo método dialético. Além da auto-organização, encontram-se na base de seu pressuposto o princípio das relações com a realidade atual, a qual é conceituada como "tudo o que na vida social da nossa época, está destinado a viver e a se desenvolver, tudo o que se agrupa em torno da revolução social vitoriosa e que serve à organização da vida nova” (PISTRAK, 1981, p. 34).

A escola deve fundamentar-se no estudo da realidade atual, penetrá-la e vivenciá-la, reconhecendo o passado, revisitando-o à luz do presente, para que então, tal realidade presente possa ser transformada. Em sua concepção, é importante que exista um casamento entre teoria e prática, para que a educação tenha fundamento na realidade e que desta maneira se possa modificá-la.

Assim, a obra de Pistrak (1981) nos revela que sem teoria pedagógica revolucionária não é possível haver uma prática pedagógica revolucionária. Sem uma teoria de pedagogia social a prática levará a uma acrobacia sem finalidade social, utilizada para resolver os problemas pedagógicos de modo reducionista e não na base de concepções sociais bem determinadas.

Faz-se necessário ressaltar que a escola do trabalho foi concebida em um momento em que a Rússia passava por grandes e significativas mudanças. Momento este em que a classe proletária era oprimida pela burguesia, sendo a escola um dos principais instrumentos de dominação e manutenção do status quo. Por meio da escola do Trabalho, Pistrak propõe uma escola que deve viver no seio da realidade, adaptando-se a ela e reorganizando-se (PISTRAK, 1981). "A ideia básica de uma nova sociedade, que realizaria a fraternidade e a igualdade, o fim da alienação, era uma imensa esperança coletiva que tomou conta da sociedade soviética entre 1918 e 1929” (TRAGTENBERG, 1981, p. 8).

A chamada auto-organização dos estudantes tem importância fundamental nessa proposta de pedagogia social, com objetivos explícitos no sentido de não perder de vista que o estudante não está se preparando para ser membro da sociedade, ele já é e têm seus problemas, interesses, objetivos e ideais, já está ligado à vida dos adultos e à própria vida em sociedade (PISTRAK, 1981). "O trabalho na escola, enquanto base da educação, deve estar 
ligado ao trabalho social, à produção real, a uma atividade concreta socialmente útil..." (p. 39). Nesta concepção, percebe-se que não é possível introduzir o trabalho na escola se este for considerado de uma forma abstrata, como uma disciplina isolada e separada do principal aspecto: a realidade atual.

Ao discutir currículo, didática e avaliação, Freitas $(1998 ; 2009)$ nos apresenta autores russos do século passado e, especificamente com Pistrak, estabelece um rico debate sobre a educação, propondo uma comparação entre as mudanças da educação na implantação do socialismo pela Revolução Russa e no Brasil, na década de 1980, nas lutas pela democratização do ensino no país. A partir deste contexto, se discute um sistema didático em que os objetivos do ensino desempenham papel fundamental e estão calcados na experiência social, fundamentam-se nos seguintes componentes da educação: “a) o conhecimento (da natureza, da sociedade, da técnica, do homem e do pensamento); b) as habilidades para usar este conhecimento de maneira ativa; c) a atividade e d) as atitudes emocional-valorativas para com o mundo, as pessoas e para si mesmo" (p. 30).

De acordo com Freitas (2018) é a partir da integração destas quatro grandes áreas que se define o conteúdo da escola, conclui: "se conhecemos os objetivos do ensino, sabemos o que ensinar, isto é, o conteúdo" (p. 30). Nota-se que as duas categorias que abrem a abordagem didática, propriamente dita, são os objetivos e o conteúdo do ensino (calcados na experiência social). Estas áreas devem desempenhar certas funções na cultura e na formação da personalidade do aluno, a saber: a) o conhecimento possui função ontológica, orientadora e valorativa; b) as habilidades para usar o conhecimento representam funções ligadas à reprodução da cultura social; c) a atividade criativa tem funções de transformação e desenvolvimento da cultura social; e d) as atitudes emocional-valorativas estão ligadas a funções de escolha articuladas com as demandas e motivações.

Em que pese não ser possível trazer aqui toda riqueza dos estudos de Pistrak e seus contemporâneos, Freitas (1998) aponta que o ensinamento que se pode retirar refere-se a um possível estreitamento de relações entre as áreas do currículo e da didática, numa perspectiva de construção de um sistema enquanto teoria do processo de ensino. Deste modo, o campo que emerge desta junção é o da organização do trabalho pedagógico da escola, cuja maior beneficiária seria a didática, já que o currículo abre perspectivas mais amplas de atuação e retira a ação pedagógica do estrito limite da sala de aula, permitindo que se visualizem outras relações com a sociedade.

Ainda de acordo com este pensamento, Freitas (1998) reitera que esta proposta supera, em muito, a tradicional abordagem que divide o conteúdo escolar nas áreas cognitiva, afetiva 
e psicomotora. De modo complementar, distingue as "formas de realização do ensinoaprendizagem" e "formas organizacionais" para não falar da amplitude da ação do currículo a partir da especificação de "formas de conteúdo" que incluem intencionalmente a dimensão da criatividade e das atitudes emocional-valorativas. (p. 32)

A concepção da Escola do Trabalho contribui para a contextualização e referencial teórico-conceitual do presente estudo, tendo em vista seu objetivo de apresentar algumas das bases da educação pelo trabalho, remetendo-a à saúde, trazendo proposições de uma ação pedagógica para além dos muros da escola, numa educação que visualiza e assume outras relações com a sociedade.

A educação pelo trabalho permite um processo formativo em saúde que toma como base a saúde como um bem de construção coletiva. Ou seja, favorece a autonomia dos sujeitos sob o processo de produção de saúde-doença-cuidado, valorizando as subjetividades nos processos do cuidado, com destaque aos "determinantes sociais, culturais e espirituais sobre as condições de vida e de saúde das pessoas, e reconhece a influência dos fatores socioeconômicos, políticos e ambientais na organização dos sistemas e serviços de saúde" (SILVA et al., 2015, p. 967).

Neste ideário, os autores compreendem que há necessidade de mudança no paradigma do processo formativo, essencialmente material, no trabalho, para o processo formativo no trabalho informal, que põe em pauta o processo de produção da subjetividade, se constitui 'fora' da relação de capital, no cerne dos processos constitutivos da intelectualidade de massa, isto é, na subjetivação do trabalho.

Deste modo, o trabalho no campo da saúde coletiva, para materialização do conceito ampliado de saúde, exige do trabalhador uma postura ética, crítica e política em defesa dos princípios do SUS, visando à superação do trabalho morto para o trabalho vivo em ato, com uso racional de tecnologias em saúde (SILVA et al., 2015). Nesse sentido, é na relação com o outro - baseando-se no conceito de integralidade que se conformam os espaços produtores de encontros permeados por subjetividades, abordagens e dimensões pedagógicas pelos atores envolvidos.

Entende-se que a formação no trabalho nos possibilita um plano de experimentação, plano onde o pensar, fazer, aprender, trabalhar e viver estão juntos. Assim, Silva et al. (2015) constatam que "não existe separação real entre trabalho em situação, em ato, e os processos de formação pelo trabalho, ou seja, durante o processo de trabalho em saúde ou educação pelo trabalho, institucionalizado ou não, existe uma produção pedagógica” (p. 967). 
A partir deste contexto, compreende-se que o PET-Saúde também apresenta uma proposta de mudanças no ensino e na formação de estudantes, professores universitários e profissionais de saúde, no qual o cotidiano do trabalho é considerado eixo de aprendizado, investindo em processo que permite a "abertura para uma práxis em saúde que acredita na potência do cotidiano dos serviços de saúde enquanto instâncias para ação-reflexão-ação, que buscam construir uma formação, que prima pelo refletir, pensar e agir não para, e sim com o outro" (SILVA et al., 2015, p. 978).

Neste intuito, apresenta-se a seguir um breve histórico do Programa de Educação Tutorial (PET) do MEC, tendo em vista o seu caráter embrionário e de base para o que viria a ser constituído como o Programa PET-Saúde, em parceria do MEC e MS já em curso no país há cerca de duas décadas.

\section{O Programa de Educação Tutorial (PET) e suas bases para desenvolvimento do PET- Saúde}

Em 1979, foi criado o Programa de Educação Tutorial (PET), inicialmente nomeado de Programa Especial de Treinamento pela Coordenadoria de Aperfeiçoamento de Pessoal de Nível Superior (CAPES) (BRASIL, 2006). Com o objetivo de melhorar o ensino de graduação e a qualidade dos cursos de pós-graduação, a CAPES/MEC, implantou o PET no intuito de elevar a qualificação de grupos selecionados de alunos da graduação, mediante um intenso e avançado treinamento. Desta forma, direcionou seus esforços para à formação de profissionais de alto nível para todos os segmentos do mercado de trabalho, com destaque especial para a carreira universitária (TOSTA et al., 2006).

Em 1999, o Programa teve sua gestão transferida para a Secretaria de Educação Superior (SESu/MEC), ficando sob a responsabilidade do Departamento de Modernização e Programas de Educação Superior (DEPEM). O Programa foi organizado de forma que os alunos, a partir de grupos de aprendizagem, tivessem a possibilidade de desenvolver atividades extracurriculares, supervisionadas por um professor-tutor (NEVES, 2003; BRASIL, 2006).

O PET foi oficialmente instituído pela Lei 11.180/2005 (BRASIL, 2005) e regulamentado por diversas portarias que regularam o funcionamento do programa a partir de sua constituição administrativa e acadêmica, além de estabelecer normas e periodicidade no processo de avaliação nacional dos grupos. Por meio de uma nova portaria de 2010, foram trazidas inovações para a estrutura de seu funcionamento, como a flexibilização e 
dinamização da estrutura dos grupos, a união do PET com o "Conexões de Saberes", a definição de tempo máximo de exercício da tutoria, maior aproximação com a estrutura acadêmica da universidade e a definição de estruturas internas de gestão (BRASIL, 2010).

O modelo de ensino tutorial estimulava a proatividade dos integrantes do PET e, através de vivências, discussões e reflexões, permitia uma aprendizagem sólida para que desenvolvam capacidade de pensamento crítico e habilidade para resolução de problemas. As atividades extracurriculares dos grupos foram balizadas nos elementos do tripé ensinopesquisa-extensão, favorecendo a entrada em programas de pós-graduação e no mercado de trabalho (LEITE et al., 2016).

O PET foi desenvolvido para o trabalho com pequenos grupos de estudantes, com tutoria de um docente, organizados a partir de cursos de graduação das Instituições de Ensino Superior (IES) do país. Neste arranjo, os grupos foram constituídos por cursos e orientados pelo princípio da indissociabilidade entre ensino, pesquisa e extensão. Entre seus principais objetivos foram apontadas as necessidades de desenvolver: atividades acadêmicas em padrões de excelência, mediante grupos de aprendizagem tutorial de natureza coletiva e interdisciplinar; contribuir para a elevação da qualidade da formação dos alunos; promover a formação de profisssionais e docentes de elevada qualificação técnica, científica, tecnológica e acadêmica; formular novas estratégias de desenvolvimento e modernização do ensino superior no país, além de estimular a atuação profissional pautada pela ética, cidadania e pela função social da educação superior" (BRASIL, 2009).

O PET representou muitos avanços para a formação, como podemos constatar em resultados significativos, como a experiência da Universidade do Rio Grande do Sul que, ao nos apresentar o conceito de educação tutorial, ressalta que "A lógica de compreensão é coletiva, se rompe do papel aluno-professor e se institui uma lógica de dois estudantes de papéis similares produzindo noções de igualdade e cidadania" (SILVA, 2010, p.118)

A tutoria proporciona aprendizagem em um ambiente menos formal que a sala de aula, aproximando tutor e aluno, desenvolvendo diferentes tipos de relações, sem que se percam as suas especificidades. Nesta oportunidade alguns grupos trabalhavam com o modelo de gestão e autogestão, outros, por sua vez, preferiam estabelecer, entre os bolsistas, coordenadorias e sub coordenadorias, para evitar a centralização de atividades (SILVA, 2010, p. 120). De acordo com esta experiência o PET potencializou a aprendizagem teórica a partir das vivências em grupo e das tutorias, propiciando autonomia aos alunos e contribuindo para a formação dos tutores. 
Neste contexto, faz-se necessário destacar que em 2005, o PET passou a ser regido por uma nova legislação a partir de sua inclusão na lei 11.180 de 2005 (BRASIL, 2005), que entre outros aspectos instituiu no âmbito do MEC, o Programa de Educação Tutorial - PET, destinado a fomentar grupos de aprendizagem tutorial mediante a concessão de bolsas de iniciação científica a estudantes de graduação e bolsas de tutoria a professores tutores de grupos do PET.

Ressaltamos que o PET, instituído pelo MEC, o qual denominamos PET-MEC teve uma dotação orçamentária consignada ao MEC e ao Fundo Nacional de Educação (FNDE), o que significou uma certa segurança em relação a permanência e subsistência do programa, conforme a legislação atual. Neste cenário, sua experiência foi fundamental para estruturação e desenvolvimento do PET-Saúde, a seguir iremos apresentar alguns de seus principais aspectos.

\section{O desenvolvimento do PET-Saúde nas últimas duas décadas}

A implantação da lei de diretrizes e bases da educação nacional de 1996 (LDB/1996) (BRASIL, 1996) e das diretrizes curriculares nacionais (DCN) para os cursos de graduação na saúde de 2001 e 2002, provocaram várias mudanças, dentre as quais se destaca a proposta de formação de profissionais preparados para responder às necessidades de saúde da população e do sistema de saúde público do país, o SUS, diversificando os cenários de ensino e aprendizagem, em direção à atenção primária em saúde (APS) e passaram progressivamente a integrar o cotidiano das unidades básicas de saúde (UBS).

Tanto o MS quanto o MEC, em ação conjunta, têm promovido nas últimas décadas várias iniciativas para estimular a aproximação das Instituições de Ensino Superior com os serviços de saúde no SUS, com ênfase na APS, como o Programa de Incentivo às Mudanças Curriculares das Escolas Médicas (Promed), o Programa Nacional de Reorientação da Formação Profissional em Saúde (Pró-Saúde) e o Programa de Educação pelo Trabalho para a Saúde (PET-Saúde), entre outros.

A difusão da proposta de EPS no Brasil tem como marco o Decreto de 20 de junho de 2007, que instituiu, no âmbito do MEC e MS, a Comissão Interministerial de Gestão do Trabalho e da Educação na Saúde, em seu Art. 1 afirma seu caráter de função consultiva em relação à ordenação da formação de recursos humanos na área da saúde, de acordo com as competências estabelecidas no art. $2^{\circ}$, em conformidade com as políticas nacionais de educação e saúde e os objetivos, princípios e diretrizes do SUS (BRASIL, 2007) 
Neste contexto, uma das principais estratégias de reorientação da formação profissional induzidas pela SGTES/MS foi a implantação do Programa de Educação para o Trabalho em Saúde (PET-Saúde), em 2007. Impulsionado pelo Programa de Educação Tutorial, o PET-Saúde foi instituído pela Portaria Interministerial MS/MEC nº 1.802, de 26 de agosto de 2008. Constituiu parceria entre a SGTES, Secretaria de Atenção à Saúde (SAS) e Secretaria de Vigilância em Saúde (SVS) do MS; a Sesu do MEC e a Secretaria Nacional de Políticas sobre Drogas (Senad/GSI/PR) (BRASIL, 2013)

O PET-Saúde tem como fio condutor a integração ensino-serviço-comunidade e a indissociabilidade entre ensino, pesquisa e extensão. O programa tem por pressuposto a educação pelo trabalho na formação do profissional de saúde e a qualificação do SUS a partir da promoção e qualificação da integração ensino-serviço-comunidade, com envolvimento de docentes, estudantes de graduação e profissionais da saúde, de maneira que as necessidades dos serviços se tornem fonte de produção de conhecimento e pesquisa em temas e áreas estratégicas do SUS (BRASIL, 2018).

Neste intuito, compreende-se que o PET-Saúde também impulsiona mudanças no ensino e no serviço em saúde a partir do pagamento de bolsas para as seguintes atividades: a) iniciação ao trabalho: destinada a estudantes de graduação da área da saúde, regularmente matriculados em Instituições de Educação Superior (IES) públicas e privadas sem fins lucrativos; b) tutoria acadêmica: destinada a professores das IES integrantes do Programa; e c) preceptoria: destinada a profissionais de saúde do SUS (BRASIL, 2018).

A partir deste programa, as IES passaram a se reorganizar e repensar o processo de formação em saúde, pois além de utilizar os serviços como cenários de prática para a formação, também se fizeram necessários arranjos e pactuações junto as secretarias de saúde, mobilizando e formalizando novas parcerias para que o programa pudesse funcionar adequadamente, aproximando ainda mais o ensino da realidade do SUS e da comunidade.

O Quadro 1 apresenta todos os editais PET-Saúde publicados até o presente momento, com destaque as suas diferentes versões publicadas nos distintos editais e seus respectivos objetivos.

Quadro 1 - Editais Pet-Saúde segundo ano do edital e objetivo do programa, Brasil, 2021

\begin{tabular}{|c|l|l|}
\hline \multicolumn{1}{|c|}{ PET-Saúde } & \multicolumn{1}{|c|}{ Edital } & \multicolumn{1}{c|}{ Objetivo } \\
\hline PET-Saúde/SF 2008/2010 & $\begin{array}{l}\mathrm{N}^{\mathrm{o}} \text { 15, de 12 } \\
\text { de } \\
\text { novembro }\end{array}$ & $\begin{array}{l}\text { Ter foco na estratégia Saúde da Família } \\
\text { (PSF), como modelo da reorganização da } \\
\text { Atenção Primária em Saúde e ordenadora }\end{array}$ \\
\hline
\end{tabular}




\begin{tabular}{|c|c|c|}
\hline & de 2008 & \multirow{2}{*}{$\begin{array}{l}\text { das redes de atenção à saúde no Sistema } \\
\text { Único de Saúde (SUS). }\end{array}$} \\
\hline PET-Saúde/SF 2009/2012 & $\begin{array}{l}\mathrm{N}^{\mathrm{o}} 18, \text { de } 16 \\
\text { de setembro } \\
\text { de } 2009\end{array}$ & \\
\hline PET-Saúde/VS - 2010/2012 & $\begin{array}{l}\mathrm{N}^{\mathrm{o}} 07, \text { de } 03 \\
\text { de março de } \\
2010\end{array}$ & $\begin{array}{l}\text { Fomentar a formação de grupos de } \\
\text { aprendizagem tutorial na área de Vigilância } \\
\text { em Saúde. }\end{array}$ \\
\hline PET-Saúde/SM 2011/2012 & $\begin{array}{l}\text { No } 27 \text {, de } 17 \\
\text { de setembro } \\
\text { de } 2010\end{array}$ & $\begin{array}{l}\text { Fomentar grupos de aprendizagem tutorial no } \\
\text { âmbito da Atenção em Saúde Mental: Crack, } \\
\text { álcool e outras drogas, visando a qualificação } \\
\text { da formação dos estudantes dos cursos da } \\
\text { área da saúde e dos profissionais da Saúde } \\
\text { Mental. }\end{array}$ \\
\hline $\begin{array}{l}\text { Pró-Saúde/PET-Saúde } \\
2011 / 2014\end{array}$ & $\begin{array}{l}\text { No } 24, \text { de } 15 \\
\text { de dezembro } \\
\text { de } 2011\end{array}$ & $\begin{array}{l}\text { Mobilizar instituições de ensino superior do } \\
\text { País, em parceria com as secretarias } \\
\text { municipais e estaduais de Saúde e com a } \\
\text { participação da comunidade, na maior } \\
\text { integração ensino-serviço, a centralidade na } \\
\text { produção de saúde e no cuidado humanizado } \\
\text { na formação da graduação das profissões da } \\
\text { área da Saúde. }\end{array}$ \\
\hline PET-Saúde/VS - 2012/ 2015 & $\begin{array}{l}\mathrm{N}^{\mathrm{o}} 28, \text { de } 22 \\
\text { de } \\
\text { novembro } \\
\text { de } 2012\end{array}$ & $\begin{array}{l}\text { Fomentar a formação de grupos de } \\
\text { aprendizagem tutorial na área de Vigilância } \\
\text { em Saúde. }\end{array}$ \\
\hline $\begin{array}{l}\text { PET-Saúde/Redes } \\
\text { 2013/2015 }\end{array}$ & $\begin{array}{l}N^{o} 14, \text { de } 8 \\
\text { de março de } \\
2013\end{array}$ & $\begin{array}{l}\text { Desenvolver intervenções na modelagem das } \\
\text { redes de atenção à saúde visando a } \\
\text { qualificação das ações e serviços de saúde } \\
\text { oferecidos à população nos diversos pontos } \\
\text { de atenção das redes e a inserção das } \\
\text { necessidades dos serviços no contexto das } \\
\text { redes como fonte de produção de } \\
\text { conhecimento e pesquisa nas instituições de } \\
\text { ensino. }\end{array}$ \\
\hline $\begin{array}{l}\text { PET-Saúde/Gradua } \quad \text { SUS } \\
2015 / 2017\end{array}$ & $\begin{array}{l}\text { N }^{\mathrm{o}} 13, \text { de } 28 \\
\text { de setembro } \\
\text { de } 2015\end{array}$ & $\begin{array}{l}\text { Propor mudança curricular alinhada às } \\
\text { Diretrizes Curriculares Nacionais dos cursos } \\
\text { de graduação na área da saúde e a } \\
\text { qualificação dos processos de integração } \\
\text { ensino-serviço-comunidade articuladas entre } \\
\text { o SUS e as instituições de ensino. }\end{array}$ \\
\hline $\begin{array}{l}\text { PET- } \\
\text { Saúde/Interprofissionalidade } \\
\text { 2018/2021 }\end{array}$ & $\begin{array}{ll}\mathrm{N}^{\mathrm{o}} & 10, \text { de } 23 \\
\text { de } & \text { julho } \\
2018 & \end{array}$ & $\begin{array}{l}\text { Fomentar trabalhos com foco na } \\
\text { interprofissionalidade, interdisciplinaridade, } \\
\text { intersetorialidade, em rede, integração } \\
\text { ensino-serviço e diversificação dos cenários } \\
\text { de práticas como prerrogativas para } \\
\text { mudanças, na dinâmica do trabalho em saúde, } \\
\text { fortalecendo o conceito de humanização do } \\
\text { cuidado e o princípio da integralidade da } \\
\text { assistência no contexto das redes }\end{array}$ \\
\hline
\end{tabular}


colaborativas na formação para o SUS;

A partir do exposto, é importante destacar que não há uma legislação própria que inclua o PET-Saúde, como a do PET-MEC, aqui descrita, o que, de certa maneira, significa uma fragilidade de sua sustentação, na medida que sempre existiu como um edital, em geral com duração de dois anos consecutivos. Consideramos essa uma diferença significativa em relação a valorização do PET-Saúde e a necessidade de sua institucionalização como um programa permanente nas IES.

De modo geral, podemos sintetizar várias das dimensões e aspectos envolvidos na proposta do PET-Saúde na definição apresentada pelo MS (2013), ao salientar que "é uma inovação pedagógica que agrega os cursos de graduação da área da Saúde e fortalece a prática acadêmica que integra a universidade, em atividades de ensino, pesquisa e extensão, com demandas sociais de forma compartilhada" (p. 4). Além disso, ressalta-se o foco na interprofissionalidade, em que estudantes de diferentes formações e que estão em diversos períodos, mediados por professores de várias formações e profissionais dos serviços de saúde, aprendendo e interagindo em conjunto no cuidado para como a saúde das pessoas, famílias e comunidades.

Tendo como principais objetivos a valorização do trabalho em equipe, a integração e as especificidades de cada profisssão, o PET-Saúde, coopera, de modo técnico-financeiro, para a integração do ensinar com o trabalhar, em prol da aprendizagem e valorização da APS e da atuação em redes estratégicas, para a resolutividade das ações e serviços e a resolubilidade do sistema de atenção à saúde (GUSMAO.; CECCIM.; DRACHLER, 2015, p. 696)

Neste cenário, Oliveira (2010) afirma que o compromisso social das Instituições de Ensino Superior contribui para que projetos de extensão e pesquisa sejam construídos em ação intersetorial, envolvendo profissionais e acadêmicos em propostas que fortaleçam a formação e ações no serviço, com foco nas necessidades reais, favorecendo a promoção da saúde.

Do mesmo modo, Carvalho (2015) assume que o PET-Saúde emerge no discurso coletivo enquanto grande fomentador das ações de integração ensino e serviços, com potencial de promover a valorização do profissional e do processo de ensino. Destaca que, sob a forma de incentivo governamental, "passa a integrar o profissional de saúde ao universo do ensino-aprendizagem e proporciona valorização, conhecimento e troca de saberes, utilizando educação permanente e oportunidades de discussão dentro do ambiente da UBS” (p. 137).

Para conhecer e valorizar as experiências PET-Saúde, a revista Interface Comunicação, Educação e Saúde, em 2015, publicou um suplemento em parceria com o MS 
e a OPAS para que as Instituições de Ensino Superior pudessem relatar suas experiências ao participar do programa. Foram submetidos 397 manuscritos e o número expressivo de submissões mostrou a importância que o programa tem para as instituições de ensino. (CECCIM; CYRINO, 2017)

Devido à grande quantidade de submissões e ao pouco espaço disponível para a publicação na revista, a Rede Unida criou uma Série de quatro livros sobre a temática da integração ensino e sistemas locais de saúde, com 53 experiências em trabalhos publicados. A abertura do espaço para as publicações mostrou o grande potencial para produção de conhecimento e para a potencialidade das ações e experiências impulsionadas pelo PETSaúde.

\section{Considerações finais}

Ao trazermos Pistrak e a escola do trabalho, buscamos encontrar uma base teóricoconceitual para discutir um programa federal que objetiva influenciar a mudança nas graduações da saúde na perspectiva da maior aproximação entre a formação universitária na saúde do SUS. Foi possível identificar que nas diferentes edições do PET-Saúde, em curso há quase duas décadas, que a base permanece a mesma, a educação pelo trabalho no SUS, são inúmeras possibilidades de avanços através do compartilhamento de saberes entre universidade e serviços de saúde com intuito de qualificar a formação e os serviços de saúde.

Apresentamos o PET-MEC como uma referência, no sentido de trazer um programa existente, com financiamento do MEC, há cerca de 40 anos e com sucesso, no sentido de aproximar as instituições de ensino superior, os professores e estudantes de ações de ensino articuladas à pesquisa e extensão. Também o trouxemos na medida em que há referência do programa ter sido uma base para a construção do PET-Saúde e assim pudemos conhecer um pouco mais sobre suas bases conceituais.

O PET-Saúde é reconhecido como um projeto com dimensão ampla, buscando a possibilidade da educação pelo trabalho e a educação permanente dos profissionais que estão atuando no SUS, com certa ênfase na formação na APS articulada às redes de atenção. Todavia, para que a mudança nas graduações ocorra com o apoio no desenvolvimento do PET-Saúde, seus objetivos político-pedagógicos devem se concretizar nos processos educativos, dentro e fora das universidades, com a interdisciplinaridade, a interprofissionalidade, a integração de conhecimentos no currículo, a produção do 
conhecimento, e influenciar o ensino das disciplinas, módulos e atividades de formação de estudantes, população, professores e profissionais de saúde.

Os dois Programas, PET-MEC e PET-Saúde, nas suas diferentes versões, persistem e buscam fortalecer a tríade ensino, pesquisa e extensão, assim como vem favorecendo uma formação mais comprometida e preocupada com a realidade atual, concatenando teoria e prática em compromisso com a práxis social.

Vimos que a partir do PET-MEC foi possível ampliar a qualificação da graduação na área da saúde através de experiências interdisciplinares, extracurriculares, com o foco no mercado de trabalho e a formação de professores/pesquisadores para a carreira universitária. O PET-Saúde por sua vez, amplia o escopo ao voltar-se à valorização da formação pelo trabalho a partir da qualificação dos serviços de saúde, preocupando-se com a realidade local no intuito de transformá-la. Além disso, estimula parcerias e arranjos com secretarias e serviços de saúde que vão muito além dos muros da universidade.

Devemos citar que há uma dimensão essencial que diferencia os dois programas, a forma de financiamento. Por tudo que conseguimos analisar nos documentos estudados, o PET-MEC tem um recurso pré-estabelecido no MEC e assim tem uma garantia de continuidade e permanência muito superior ao PET-Saúde, que depende de editais para sua sobrevivência, o que the confere maior fragilidade e dificuldade de sustentabilidade ao longo do tempo.

O PET-Saúde avança em relação a uma formação mais engajada, voltada para a realidade atual e que favorece a auto-organização dos alunos, que são os princípios básicos da escola do trabalho apresentada por Pistrak. O autor valoriza exatamente esta questão: uma educação que está articulada ao trabalho e a realidade, uma formação que se fundamenta no estudo da realidade atual, busca adentrar e viver nela, não deve ignorar o passado, que deve ser estudado à luz do presente, para transformar a realidade. Uma educação que se fundamenta na realidade e que desta maneira possa modificá-la.

Refletir sobre políticas públicas de saúde que valorizem a educação pelo trabalho, para e no SUS, nos direciona ao compromisso da integralidade do cuidado mediado por um processo de educação para a formação de sujeitos responsáveis, conscientes, críticos e que tenham maior autonomia, que sejam capazes de contribuir para a transformação de relações sociais baseadas em explorações, injustiças e iniquidades. 
AGRADECIMENTOS: Este trabalho foi realizado com apoio da Coordenação de Aperfeiçoamento de Pessoal de Nível Superior - Brasil (CAPES) 2237/2010, Projeto PróEnsino na Saúde da Faculdade de Medicina de Botucatu/ UNESP (2010-2018), Edital CAPES 24/2010 Pró Ensino na Saúde e traduz o trabalho colaborativo do Grupo de Pesquisa do Projeto: Integração Universidade, Serviços de Saúde e Comunidade na Faculdade de Medicina de Botucatu/UNESP: Construindo novas práticas de formação e pesquisa.

\section{REFERÊNCIAS}

BRASIL. Ministério da Educação. Secretaria de Educação Superior. Programa Especial de Treinamento: Manual de Orientações Básicas - PET. Brasil. 2002. Disponível em: http://portal.mec.gov.br/sesu/arquivos/pdf/PETmanual.pdf. Acesso em: 07 jun. 2018

BRASIL. Portaria n ${ }^{\circ} 198$ GM/MS, de 13 de fevereiro de 2004. Institui a Política Nacional de Educação Permanente em Saúde como estratégia do Sistema Único de Saúde para a formação e o desenvolvimento de trabalhadores para o setor e dá outras providências. Diário Oficial da União. 2004.

BRASIL. Presidência da República. Casa Civil Subchefia para Assuntos Jurídicos. Lei no 11.180, de 23 de setembro de 2005. Disponível em: http://portal.mec.gov.br/index.php?option=com_docman\&view=download\&alias=332 leisetembro2005\&category_slug=pet-programa-de-educacao-tutorial\&Itemid=30192. Acesso em: 13 jul. 2019.

BRASIL. Ministério da Educação. Manual de Orientações - PET. 2006 Disponível em: http://portal.mec.gov.br/index.php?option $=$ com_content\&view $=$ article \&id $=12228 \&$ Itemid $=4$ 86/. Acesso em: 03 maio 2018.

BRASIL. Ministério da Saúde. Ministério da Educação. Portaria Interministerial no 1.507, de 22 de junho de 2007. Institui o Programa de Educação pelo Trabalho para a Saúde - PETSaúde. Brasília: 2007.

BRASIL. Ministério da Saúde. Portaria No 421, de 3 de março de 2010. Institui o Programa de Educação pelo Trabalho para a Saúde (PET Saúde) e dá outras providências. Diário Oficial da União, 3 mar 2010.

BRASIL Ministério da Educação. Secretaria de Educação Superior. Portaria n⿳0 976, de 27 de julho de 2010 -- dispõe sobre o Programa de Educação Tutorial - PET.

BRASIL. Ministério da Saúde. Secretaria de Gestão do Trabalho e da Educação na Saúde. Edital $n^{\circ} 13$, de 28 de setembro de 2015. Seleção para o Programa de Educação Pelo Trabalho Para a Saúde: PET-Saúde/GraduaSUS - 2016/2017. Diário Oficial da União. 29 Set. 2015.

BRASIL. Ministério da Saúde (MS). Edital n²4, de 15 de dezembro de 2011. Seleção de projetos de instituições de educação superior para participação no Programa Nacional de 
Reorientação da Formação Profissional em Saúde articulado ao Programa de Educação pelo Trabalho para a Saúde. Diário Oficial da União, 16 dez. 2011.

BRASIL. Ministério da Saúde. Secretaria de Gestão do Trabalho e da Educação na Saúde. Edital no 10, 23 de julho 2018. Seleção para o Programa de Educação pelo Trabalho para a Saúde PET-Saúde/Interprofissionalidade - 2019/2019. Diário Oficial da União, edição 141, seção 3, página 78. 2018.

BRASIL. Ministério da Saúde. Secretaria de Gestão do Trabalho e da Educação na Saúde. Edital $\mathrm{n}^{\circ}$ 14, de 08 de março de 2013. Seleção para o Programa de Educação Pelo Trabalho Para a Saúde/Rede de Atenção à Saúde 2013/2015. Diário Oficial da União. 11 Mar 2013.

BRASIL. Ministério da Educação, Sistema de Gerenciamento de Bolsas. Perguntas Frequentes - PET. Disponível em: http://sigpet.mec.gov.br/principal/perguntas-frequentes. Acesso em: 07 jun. 2018.

BRASIL. Ministério da Saúde. Folder pró-saúde PET-Saúde. Disponível em: http://bvsms.saude.gov.br/bvs/folder/pro_saude_pet_saude.pdf. Acesso em: 07 jun. 2018.

CARDOSO, M. L. M. et al. A Política Nacional de Educação Permanente em Saúde nas Escolas de Saúde Pública: reflexões a partir da prática. Ciênc. saúde coletiva [online], vol.22, n.5, p.1489-1500, 2017.

CARVAlHO, S. B. O.; DUARTE, L. R.; GUERRERO, J. M. A. Parceria na educação e trabalho em uma unidade básica de saúde como cenário de aprendizagem/ aprendizagem. Trab. educ. saúde [online], vol.13, n.1, p.123-144, 2015.

CECCIM, R. B.; CYRINO, E. G. O sistema de saúde e as práticas educativas na formação dos estudantes da área. In: CECCIM, Ricardo Burg.; CYRINO, Eliana Goldfarb (Orgs.) Formação profissional em saúde e protagonismo dos estudantes: percursos na formação pelo trabalho. Porto Alegre: Rede UNIDA, 2017.

CECCIM, R. B.; FEUERWERKER, L. C. O quadrilátero da formação para a área da Saúde: Ensino, Gestão, Atenção e Controle Social. Revista de Saúde Coletiva, v.14, n.1, p.41-65, 2004.

CYRINO E. G. et al. O Programa Mais Médicos e a formação no e para o SUS: por que a mudança? Esc. Anna Nery, Rio de Janeiro, v. 19, n. 1, p. 5-6, 2015 a.

CYRINO, E. G. et al.. Há pesquisa sobre ensino na saúde no Brasil?. ABCS Health Sciences, v. 40, p. 146-156, 2015 b.

CUNHA, M. I. A Avaliação da aprendizagem no ensino superior. Avaliação. Rev. Rede Avaliação Instituc. Educ. Superior, Campinas, v. 4, n.14, p. 7-13, 1999.

FREITAS, L. C. Interações Possíveis entre a Área de Currículo e a Didática: o Caso da Avaliação. Pro-Posições, v.9, n. 3 (27) p.28- 42, 1998.

FREITAS, L. C. A luta por uma pedagogia do meio: revisando o conceito. In: Pistrak. M. M. A escola comuna. SP: Expressão Popular, 2009. 
GOMES, A. P.; REGO, S. Transformação da Educação Médica: É Possível Formar um Novo Médico a partir de Mudanças no Método de Ensino-Aprendizagem? Revista Brasileira de Educação Médica. v. 35, n.4, p.557-566, 2011.

GUSMAO, R. C.; CECCIM, R. B.; DRACHLER, M. L. Tematizar o impacto na educação pelo trabalho em saúde: abrir gavetas, enunciar perguntas, escrever. Interface (Botucatu), Botucatu, v. 19, supl. 1, p. 695-707, 2015.

HADDAD, A. E. et al. Pró-Saúde e PET-Saúde: a construção da política brasileira de reorientação da formação profissional em saúde. Rev Bras Educ Med. [online]. v.36 (supl1), p.3-4, 2012.

LEITE, P. H. N. et al. Programas de educação pelo trabalho e tutorial: diferentes enfoques dos grupos 'PET' no Brasil. Medicina (Ribeirão Preto). v.49, n.4, p.381-387, 2016.

NEVES, M. C. D. et al. Reinventando a graduação - Os grupos do Programa de Educação Tutorial (PET) da UEM. Maringá: Massoni, 2005.

OLIVEIRA, M. L. et al. PET-Saúde: (In)formar e Fazer como Processo de Aprendizagem em Serviços de Saúde. Rev Bras Educ Med. [online]; v.36 (1, Supl. 2): p.105-111, 2012.

PEREIRA, I. D. et al. Princípios pedagógicos e relações entre teoria e prática na formação de agentes comunitários de saúde. Trab. Educ. Saúde, Rio de Janeiro, v. 14 n. 2, p. 377-397, 2016

PISTRAK, M. (1924) Fundamentos da escola do Trabalho: uma pedagogia social. São Paulo: Ed. Brasiliense, 1981.

PISTRAK, M. (Org.) A escola-comuna. São Paulo: Expressão Popular, 2009.

PISTRAK, M. Ensaio sobre a escola politécnica. 1.ed. São Paulo: Expressão Popular, 2015.

RAMOS, M. Educação pelo Trabalho: possibilidades, limites e perspectivas da formação profissional. Saúde e Sociedade, v.18, supl.2, p.55-59, 2009.

RIBEIRO, E. C. O.; MOTTA, J. I. J. Educação Permanente como estratégia na reorganização dos serviços. Divulg. Saúde Debate, v.12, p.33-44, 1996.

SILVA, A. L. F. et al. Saúde e educação pelo trabalho: reflexões acerca do PET-Saúde como proposta de formação para o Sistema Único de Saúde. Interface (Botucatu), Botucatu, v. 19, supl. 1, p. 975-984, 2015.

TRAGTENBERG, M. Pistrak: uma pedagogia socialista. In: PISTRAK, Moisey

M. Fundamentos da Escola do Trabalho. São Paulo: Ed. Brasiliense, 1981. p.7-25.

SAVIANI, D. Escola e democracia: teorias da educação, curvatura da vara, onze teses dobre a educação política. Campinas. Ed. Autores Associados, 2006. p 66-76. 
SORDI, M. R. L. et al. Olhares avaliativos informais: o PET-Saúde - Programa de Educação pelo Trabalho para a Saúde - em tela. Interface (Botucatu), v.19, suppl.1, p.687-689. 14143283, 2015.

TOSTA, R. M. et al. Programa de educação tutorial (PET): uma alternativa para a melhoria da graduação. Psicol. Am. Lat., México, n. 8, 2006.

\section{Como referenciar este artigo}

BRAVO, V. A. A.; PINTO, T. R.; CYRINO, E. G. A educação pelo trabalho na saúde: conexões entre formação e práticas nos serviços de saúde. Temas em Educ. e Saúde, Araraquara, v. 17, n. 00, e021013, 2021. e-ISSN 2526-3471. DOI: https://doi.org/10.26673/tes.v17i00.15039

Submetido em: 09/04/2021

Revisões requeridas em: 04/05/2021

Aprovado em: 05/06/2021

Publicado em: 28/06/2021 